\title{
A infância e sua educação: Materiais, práticas e representações (Portugal e Brasil)
}

Belo Horizonte, MG: Autêntica, 2004, 228 p.

Mônica Yumi Jinzenji

Este livro representa um dos resultados da produção do Grupo de Trabalho para a História da Infância e dos Materiais Educativos e Lúdicos (GRUIH!MU), grupo constituído por pesquisadores (as) e professores (as) de diversas instituições de ensino do Brasil e de Portugal, coordenado por Luciano Mendes de Faria Filho (Universidade Federal de Minas Gerais) e Rogério Femandes (Universidade de Lisboa) .

Diversos autores trabalham o tema infância nos contextos brasileiro e português modernos e especialmente os séculos XIX e XX. São utilizadas fontes diversificadas, de naturezas distintas, como textos legais, literatura, dbamentos escolares, tratados de pedagogia, entre outros, apresentando a infância na sua pluralidade. Assim, o conjunto de trabalhos reunidos nos apresenta a multiplicidade das "infâncias" na sociedade luso-brasileira, cada qual marcada por particularidades que denotam a própria complexidade na análise da infância como categoria histórica; desse modo, para além das divisões etárias, próprias de cada época e lugar, a infância é permeada pela sua condição de classe, gênero, raça e cultura, tais como crianças

Psicóloga. Doutoranda na Faculdade de Educação UFMG. Professora do Centro Universitário de Belo Horizonte, MG. 
enjeitadas, crianças delinqüentes, alunas, meninos em intematos, crianças pobres etc.

Apesar da multiplicidade de infâncias retratadas, o conjunto dos textos apresenta eixos comuns, sendo um deles o que impõe alguns limites à pesquisa em história da infância. A infância vivida e sentida pelas próprias crianças nos momentos históricas aqui pesquisados, dificilmente deixou registros, fazendo com que as pesquisas sejam feitas a partir da visão das adultos a seu respeito, seja pelo estudo de documentos produzidos por esses adultos, seja pela memória destes em relação ao próprio passado; o que temos acesso, então, na grande maioria das vezes, são as representações dos adultos sobre esse período da vida, o que não traduz nem esgota a vivência infantil. Nesse sentido, toma-se mais apropriado falar de uma história sobre a infância e não uma história da infância (Kuhlmann Jr., 1998) .

um outro ponto de encontro entre os textos é resultante da discussão anteriormente colocada. Na medida em que as fontes se referemao registro do adulto sdbre as crianças, os discursos acabam por se referir às possibi 7 idades de intervenção vol tadas para o sujeito infantil, seja via educação escolar, o aijado médico/higienista, a ordenação legal/penal e moral, entre outros. A infância, no conjunto das pesquisas, é vista como momento para intervenções que têm a infância não como fim último, mas como meio para se chegar a um adulto civilizado, uma sociedade harmoniosa.

O conjunto de nove textos foi organizado em torno de três temas, sendo o primeiro, intitulado Sentidas da Infância. O primeiro artigo é de autoria de Moysés Kuhlmann Jr. e Rogério Fernandes - Sobre a história da infância; Cynthia Greive Veiga discute, em seguida, sobre a Infância emodemidade: ações, saberes e sujeitose, por fim, António Gomes Ferreira e Carla Cristina Lima concluem esta primeira parte com o texto: Menores em risco social e del inqüentes no séaulo XIX e princípios do séaulo XX à luz da legislaçãoportiguesa.

Kuhlmann e Fernandes discutem os conceitos de criança e infância no sentido etimológico e as significados das diversas denominações utilizadas desde a Idade Média para as divisões e denominações geracionais. Os autores propõem a revisão da dora de Philippe Ariès, História Social da Criança e da Família, apontando a inconsistência em afimmar a ausência da percepção da especificidade infantil na Idade Média e na Antigüidade. Apontam a escola como importante instituição que irá marcar a distinção entre o mundo infantil e o mundo adulto, transformando a criança em aluno, sujeito esse que deve ser preparado para o mundo adulto. 
Os autores discutem a categoria infância e sua utilização em pesquisas historiográficas, enfatizanob a importância de relacioné-la com atrras categorias, tais como a gênero, etnia, classe social e o contexto sócio-político e aultural para não tematizá-la de forma abstrata. Abstração essa que muitas vezes condiciona o olhar adulto a uma lousca pela infância perfeita, idealizada, sem a qual acredita-se que ela não tenha existido_que algumas crianças não tiveram infância.

Veiga igualmente propõe uma superação da interpretação de Ariès para a percepção da especificicidade da infância e busca compreender o lugar da criança nas sociedades ocidentais modemas, a partir da reflexão sobre a própria modemidade. Segundo a autora, a produção da infância como período geracional distinto do adulto se coloca como desdobramento de importantes mudanças de costumes que tinham como foco a produção da condição de adulto civilizado. Substituindo comportamentos rudes e primitivos pelo hábito cortês, o adulto civilizado constituiria uma sociedade civilizada. Para a manutenção dessa sociedade harmoniosa, a criança, o quanto antes, deveria também ter suprimida a instintividade pela educação do corpo.

Segundo a autora, a modernidade reservou também uma condição específica de ser mulher: voltada para a vida familiare preparada para a formação da criança civil izada. Em consonância, sobretudo no século XIX, as pedagogias formulam princípios para a educação da criança, contribuindo para a produção da infância escolarizada.

Ferreira e Lima analisam, a partir de registros judiciais de meados do século XIX às primeiras décadas do século XX, as conceppções de marginalidade, as punições previstas para os atos ilegais cometidas e o lugar da criança nessa codificação penal. O estudo dos códigos Penais do período indica mudanças que tendem para uma atenção mais cuidadosa em relação às crianças, além de um tratamento mais humano e justo, uma vez que se passa a pensar na punição tendo como fim, a recuperação do infrator e a segurança da sociedade, não unicamente como reclusão. Educação e profissional ização passam a ser recursos uti i izados para a atenuação da criminalidade. Na transição entre os séaulos, os autores ressal tam a elaboração de um direito penal próprio para menores, ainda que, desde meados dos oitocentos, a idade cronológica tenha sido referência para a definição das penas e para a determinação da imputabilidade.

A segunda parte do livro tem como tema Faces da exclusão e agnupa os textos de Alberto Lopes, A colônia precisa de crianças: consideraçães sobre o projeto de envio de menores para Angola (1927- 
1934) ; José Gonçalves Gondra, FiIhos da sambra: as "engeitadbs" camo problema da "Hygiene" no Brasil e João Amado, Pequenos guerreiros e caçadbres: folclore bélico e cinegético das crianças pobres, na dora de AquiIinoRibeiro.

Lopes investiga um projeto do Comissariado Geral de Angola (1927) que propunha o envio das crianças órfãs, abandonadas sob tutela do Estado e as internadas em casas de correção em Portugal no processo de manutenção do império colonial em Angola. Para a mesma finalidade, passariama ser enviados para lá os criminosos condenados ao degredo, o que corresponderia a beneficiar a metrópole duplamente: libertar-se de elementos nocivos e indesejados e uti lizar essa mão-de-obra para benefício do Estado. Erra previsto também o envio de Missões religiosas para a instrução e formação moral das crianças enviadas, numa intenção de disseminar a fé católica e combater as demais crenças religiosas e também civilizara colônia.

Gondra analisa, a partir de teses da Faculdade de Medicina do Rio de Janeiro datadas de 1855 a 1859, as argumentos utilizados para a difusão da medicina higienista. Entre eles, a discussão en relação ao recolhimento dos expostos, aja institucionalização explicitava o caráter moral-religioso inconporado pelo disarso médico. Essa aliança visava a difundir e reforçar o cristianismo e também legitimar, através dela, as intervençães na sociedade com práticas higienistas, prescrevenob a localização, caracterização e funciona- 
mento dos hospícios dos enjeitados, além de propor a profissionalização das amas de leite.

Amado visita a literatura portuguesa do início do século XX e, na obra do escritor Aquil ino Ribeiro, analisa como a criança pobre é retratada nas suas condições de vida e práticas lúdicas, em especial nas brincadeiras violentas e predadoras, seja dirigidas a outras crianças ou a pequenos animais. Através da análise de textos que retratam essas situações, o autor afi ima poder compreender melhor as práticas e a materialidade que constituíam o universo lúdico da criança, permitindo uma aproximação da vivência alltural infantil, au seja, a produção dos próprios brinquedos elorincadeiras.

Na terceira parte deste livro, intitulada Desafios da escolarização da infância, a literatura é util izada também como fonte no texto $O$ intemato em algumas cbras literárias portuguesas dos anos 40, de Margarida Lauro Felgueiras. A autora utiliza como fonte 0 romance de intemato, produção de caráter autobiográfico e que se caracteriza pela crítica à organização monacal e mi litar que marcava esses estabelecimentos. Essa crítica veiculava as transformaçães na sociedade e as novas concepçães pedagógicas que passaram a questionar a educação dos internatos no contexto de produção dessas doras.

Esse gênero literário tem como marca a adblescência e a formação e permite, segundo a autora, aproximar-nos das experiências desses alunos intemos, em confronto com o que foi institurdo pelas regras e determinaçães do adulto, abrindo a passibilidade de conhecer os intematos por um outro viés. A concentração de produçães de romances de internato no período analisado e a ausência de uma produção a partir da ótica feminina num momento em que os intematos femininos eram mais numerosos que as masculinos são questões colocadas para reflexão.

Ainda na terceira parte, Luciano Mendes de Faria Filho e Irlen Antânio Gonçalves discutem o Processo de escolarização e obrigatoriedade escolar: o caso de Minas Gerais (1835-1911). Tomando como fonte a legislação e relatórios de Presidentes da Província e do Estado de Minas Gerais no período. Os autores analisam a obrigatoriedade de matrícula e freqüência à escola na sua relação com as famílias e o pensamento pedagógico em circulação. Os autores apontam que, se por um lado a elaboração de leis demonstrava a preocupação e os esforços na organização e desenvolvimento da instrução pública em Minas Gerais, por outro, uma série de documentos apontavam as incoerências e a inviabilidade de uma série de determinações legais, tais como o pagamento de multas por parte das famílias, geral- 
mente pobres, que descumprissem as normas. O texto nos mostra também que, desde o início do século XIX, a carência de recursos financeiros para o desenvolvimento da Instrução pública era apontada como dostáculo para o progresso do ensino.

Os autores ressaltam a complexidade inerente ao tratamento do tema, uma vez que a idéia de obrigatoriedade traz implícito um conjunto de questões: dorigatoriedade de matrícula, freqüência e/ou aprendizado. Indicam também que, ao legislar e pretender estabelecer deveres a famílias e conseqüentemente às crianças, a partir de critérios etários, esses discursos acabam por produzir ou traduzir e reforçar a compreensão de modos adequados de socialização, tendo como referencial principal a escolarização, para os sujeitos infantis.

Maria Cristina Soares de Gouvêa, em Meninas nas salas de aula: dil lemas da escolarização feminina no séailoXIX, disate a escolarização das meninas no contexto mineiro dos oitocentos, utilizando como fontes a legislação educacional, relatórios de delegados de ensino e mapas de freqüência de escolas elementares. A autora contextualiza o processo de escolarização das meninas artiaulando-o com a inserção das mulheres no mundo do trabalho desde o período colonial e desconstrói a imagem de mulher restrita ao espaço doméstico.

Ao tratar de diversos níveis e modalidades de educação da meni$\mathrm{na} /$ mulher - a instrução elementar, os intematos, a escola nomal e a edicação doméstica - a autora aponta 
para as distintas experiências de formação dessas mulheres, situando-as e diferenciando-as de acordo com o respectivo pertencimento social, racial e geracional. A tensa relação entre a família e a escola e o desconforto causadb pela presença feminina nas escolas, seja como professoras, seja como alunas, refletiana legislação que utilizava a associação entre sexo e idade cronológica como critério para determinar a organização das escolas publicas.

Esse conjunto de trabalhos nos possibil ita refletir sobre como a infância foi pensada, que lugares foram a ela (s) reservado(s) no discurso da modemidade. A impossibilidade de se pensar, pesquisar e considerar a infância do passado no singular nos remete às múltiplas infâncias do presente, arjas vivências, acessiveis auma consulta direta, certamente nos revelariamexperiências de exclusão e de privilégio, de alegria e sofrimento, entre muitas autras.

REFERÊNCIA BIBLIOGRÁFICA

Kỉhlmann Jr. , M. (1998). Infância e educação infant il - uma abordagem histórica. Porto Alegre, RS: Mediação.

Recebidb emagosto/2004.

Aceito em setembro/2004. 